\title{
Analisis Beban Kerja dengan Menggunakan Metode Recommended Weight Limit (RWL) di PT. Indah Kiat Pulp and Paper. Tbk
}

\author{
Denny Astrie Anggraini ${ }^{1}$, Riko Ahmad Daus ${ }^{2}$ \\ Program Studi Teknik Industri Universitas Muhammadiyah Riau \\ Jalan Tuanku Tambusai Ujung Pekanbaru \\ Email : d_nny0204@yahoo.com ${ }^{1}$, rikoahmaddaus@gmail.com²
}

\begin{abstract}
Abstrak
PT. Indah Kiat Pulp and Paper adalah suatu perusahaan yang bergerak di bidang manufaktur pembuatan pulp (bubur kertas) dan paper (kertas), merupakan salah satu perusahaan yang telah menerapkan perbaikan-perbaikan budaya kerja demi tercapainya kedisiplinan di dalam perusahaan, sehingga menimbulkan suasana yang aman dan nyaman dalam bekerja. Namun demikian masih banyaknya ditemukan aktivitas pekerjaan yang tidak mementingkan ergonomic dalam bekerja sehingga dapat menyebabkan penyakit akibat kerja, seperti pekerjaan penyusunan box ream kertas secara manual yang disusun pada pallet. Berdasarkan hasil wawancara dengan operator diperoleh informasi bahwa rasa pegal pada pinggang dan punggung terjadi sebagai akibat sikap kerja yang kurang baik dan berat beban angkat yang besar. Metode yang digunakan dalam penelitian adalah metode Recommended Weight Limit $(R W L)$, untuk menganalisis terhadap kekuatan manusia dalam mengangkat atau memindahkan beban, dan merekomendasikan batas beban yang dapat diangkat oleh manusia tanpa menimbulkan cedera meskipun pekerjaan tersebut dilakukan secara berulang-ulang dan dalam jangka waktu yang cukup lama. Dari hasil penelitian dapat disimpulkan bahwa untuk berat beban yang direkomendasikan adalah $0,95 \mathrm{~kg}$ dan jarak antara conveyor dan pallet yaitu $25 \mathrm{~cm}$ serta untuk ketinggian pallet ditambah hingga $20 \mathrm{~cm}$. Usulan ini dapat mengurangi resiko cedera punggung pada pekerja.
\end{abstract}

Kata kunci : Beban Kerja, Ergonomic, Recommended Weight Limit (RWL)

\section{Pendahuluan}

PT. Indah Kiat Pulp and Paper adalah suatu perusahaan yang bergerak di bidang manufaktur pembuatan pulp ( bubur kertas ) dan paper (kertas), merupakan salah satu perusahaan yang telah menerapkan perbaikan-perbaikan budaya kerja demi tercapainya kedisiplinan di dalam perusahaan, sehingga menimbulkan suasana yang aman dan nyaman dalam bekerja.

Namun demikian masih banyaknya ditemukan aktivitas pekerjaan yang tidak mementingkan ergonomic dalam bekerja sehingga dapat menyebabkan penyakit akibat kerja, seperti pekerjaan penyusunan box ream kertas secara manual yang disusun pada pallet. Pada proses penyusunan box, operator yang bekerja seringkali merasakan keluhan berupa rasa pegal pada pinggang dan punggung. Berdasarkan hasil wawancara dengan operator diperoleh informasi bahwa rasa pegal pada pinggang dan punggung terjadi sebagai akibat sikap kerja yang kurang baik dan berat beban angkat yang besar. Pada proses ini operator memindahkan box yang sudah terisi dari meja conveyor ke sebuah pallet. Setiap box berisi 510 ream kertas yang beratnya $12-24 \mathrm{~kg}$. Satu pallet terdiri dari 60 box dengan posisi menumpuk yaitu $4 \times 3$ dengan 5 tumpukan. Posisi pengangkatan yang dilakukan oleh setiap operator dapat dilihat pada Gambar.

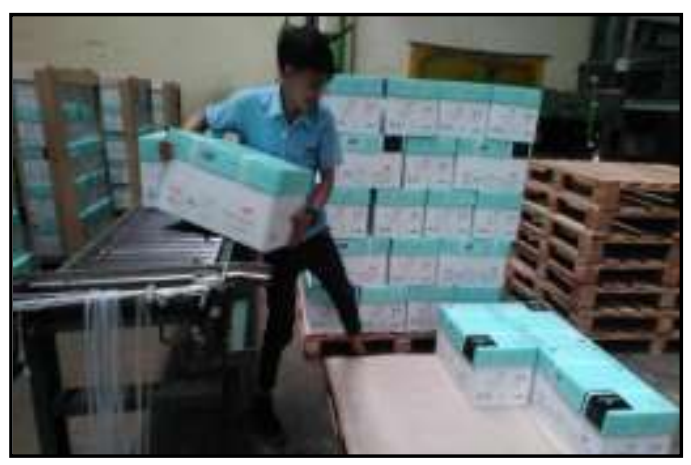

Gambar 1. Kondisi Riil Posisi Pengangkatan 
Tabel 1.

Data Kondisi Pengangkatan

\begin{tabular}{lc}
\hline \multicolumn{1}{c}{ Jarak } & Data rill lapangan \\
\hline Jarak pallet ke conveyor & $85 \mathrm{~cm}$ \\
Jarak horizontal & $40 \mathrm{~cm}$ \\
Tinggi conveyor & $85,5 \mathrm{~cm}$ \\
Tinggi pallet & $14 \mathrm{~cm}$ \\
Lebar pallet & $97 \mathrm{~cm}$ \\
Panjang pallet & $114 \mathrm{~cm}$ \\
Tinggi box & $25 \mathrm{~cm}$ \\
Panjang box & $31 \mathrm{~cm}$ \\
Lebar box & $22 \mathrm{~cm}$ \\
Berat box & $12 \mathrm{~kg}$ \\
Tumpukan box & 5 \\
\hline Sumber : Pengambilan Data, 2016 &
\end{tabular}

Untuk mendukung pekerjaan agar dapat dilakukan lebih mudah dan lebih nyaman, salah satu yang harus dibangun adalah budaya kerja yang baik. Budaya kerja di perusahaan perlu diciptakan dan dibutuhkan untuk perkembangan perusahaan dimasa yang akan datang dalam menghadapi tantangan di dunia industri.

Untuk mengatasi keluhan yang dirasakan operator, maka perlu dilakukan analisis apakah beban kerja yang ada saat ini direkomendasikan atau tidak. Untuk mengetahui apakah beban yang ada saat ini direkomendasikan atau tidak, kita perlu menggunakan metode RWL (Recommended Weight Limit) . Metode $R W L$ menganalisis terhadap kekuatan manusia dalam mengangkat atau memindahkan beban, dan merekomendasikan batas beban yang dapat diangkat oleh manusia tanpa menimbulkan cedera meskipun pekerjaan tersebut dilakukan secara berulang-ulang dan dalam jangka waktu yang cukup lama. Laporan ini akan membahas mengenai analisis beban kerja operator penyusun box ream kertas dengan menggunakan metode Recommended Weight Limit $(R W L)$.

Recommended Weight Limit (RWL) merupakan rekomendasi batas bebanyang dapat diangkat oleh manusia tanpa menimbulkan cidera meskipun pekerjaan tersebut dilakukan secara repetitive dan dalam jangka waktu yang cukup lama. RWL ini ditetapkan oleh NIOSH pada tahun 1991 di Amerika Serikat. (Waters, et al; 1994)

a. Beban yang diberikan adalah beban statis, tidak ada penambahan ataupun pengurangan beban ditengah-tengah pekerjaan.

b. Beban diangkat dengan kedua tangan.

c. Pengangkatan atau penurunan benda dilakukan dalam waktu maksimal 8 jam.

d. Pengangkatan atau penurunan benda tidak boleh dilakukan saat duduk.

e. Tempat kerja tidak sempit.

Persamaan untuk menentukan beban yang direkomendasikan untuk diangkat seorang pekerja dalam kondisi tertentu menurut NIOSH adalah sebagai berikut (Waters, et al, 1993):

\section{$R W L=L C x H M x V M x D M x A M x F M x C M$}

Keterangan :

LC : (Lifting Constanta) konstanta pembebanan $=23 \mathrm{~kg}$

$H M$ : (Horizontal Multiplier) faktor pengali horisontal $=25 / H$

VM : (Vertical Multiplier) faktor pengali vertikal $=1-0,003[V-75]$

DM : (Distance Multiplier) faktor pengali perpindahan $=0,82$ $+4,5 / D$ AM : (Asymentric Multiplier) faktor pengali asimentrik $=1-0,0032$ $A(0)$

FM : (Frequency Multiplier) faktor pengali frekuensi

CM : (Coupling Multiplier) faktor pengali kopling (handle)

Tabel 2.

Komponen Pembentuk Persamaan RWL

\begin{tabular}{lcc}
\hline \multicolumn{1}{c}{ Komponen } & Metrik & US Customary \\
\hline $\begin{array}{l}\text { LC }=\text { Konstanta } \\
\text { Beban }\end{array}$ & $23 \mathrm{~kg}$ & $51 \mathrm{lbs}$ \\
HM = Pengali & $(25 / \mathrm{H})$ & $(10 / \mathrm{H})$ \\
Horizontal & $1-(0.003 \mid \mathrm{V}-$ & $1-(0.0075 \mid \mathrm{V}-$ \\
VM = Pengali & $75 \mid)$ & $30 \mid)$ \\
Vertikal & $0.82+(4.5 / \mathrm{D})$ & $0.82+(1.8 / \mathrm{D})$ \\
DM = Pengali & $1-(0.0032 \mathrm{~A})$ & $1-(0.0032 \mathrm{~A})$ \\
Jarak & & \\
AM = Pengali & Dari tabel 3 & Dari tabel 3 \\
Asimetri & Dari tabel 4 & Dari tabel 4 \\
FM = Pengali & & \\
Frekuensi & & \\
KM = Pengali & &
\end{tabular}

${ }^{a}$ untuk frequensi angkatan kurang dari sekali per 5 menit, $\mathrm{F}=0,2 \mathrm{lift} / \mathrm{min}$.

Catatan :

$H=$ Jarak horizontal posisi tangan yang memegang beban dengan titik pusat tubuh. 
$V=$ Jarak vertikal posisi tangan yang memegang beban terhadap lantai

$D=$ Jarak perpindahan beban secara vertikal antara tempat asal sampai tujuan

$A=$ Sudut simetri putaran yang dibentuk antara tangan dan kaki.

Untuk Frequency Multiplier (FM) adalah :

1. Durasi pendek : 1 jam atau kurang.

2. Durasi sedang : antara $1-2$ jam.

3. Durasi panjang : $2-8$ jam.

Tabel 3.

Frequency Multiplier

\begin{tabular}{|c|c|c|c|c|c|c|}
\hline \multirow{3}{*}{$\begin{array}{c}\text { Frogencency" } \\
\text { Lift min } \\
\text { (F) }\end{array}$} & \multicolumn{6}{|c|}{$L_{2=2}$ Kefja Mengangkat } \\
\hline & \multicolumn{2}{|c|}{$\leq 1 \mathrm{jm}$} & \multicolumn{2}{|c|}{$>1 \mathrm{dm} \Omega \mathrm{jam}$} & \multicolumn{2}{|c|}{$>2 \mathrm{dmm} \leq 8 \mathrm{jmm}$} \\
\hline & Vo< 75 & $\mathrm{~V} \geq 75$ & $\mathrm{~V}<75$ & $\mathrm{~V} \geq 75$ & $\mathrm{~V}<75$ & $v \geq 75$ \\
\hline$\geq 0,2$ & 1,00 & 1,00 & 0,95 & 0,95 & 0,85 & $0.8:$ \\
\hline 0,5 & 0,97 & 0,97 & 0,92 & 0,92 & 0,81 & 0,81 \\
\hline 1 & 0,94 & 0,94 & 0,88 & 0,88 & 0,75 & 0,73 \\
\hline 2 & 0,91 & 0,91 & 0,84 & 0.84 & 0,65 & 0,65 \\
\hline 3 & 0,88 & 0,88 & 0,79 & 0,79 & 0,55 & 0.55 \\
\hline 4 & 0,84 & 0,84 & 0,72 & 0,72 & 0,45 & 0.45 \\
\hline 5 & 0,80 & 0,80 & 0,60 & 0,60 & 0,35 & 0,33 \\
\hline 6 & 0,75 & 0,75 & 0,50 & 0,50 & 0,27 & 0,27 \\
\hline 7 & 0,70 & 0,70 & 0,42 & 0,42 & 0,22 & 0,22 \\
\hline 8 & 0,60 & 0,60 & 0,35 & 0,35 & 0,18 & 0,18 \\
\hline 9 & 0,52 & 0,52 & 0,26 & 0,26 & 0,00 & 0,15 \\
\hline 10 & 0,45 & 0,45 & 0,00 & 0,23 & 0,00 & 0,13 \\
\hline 11 & 0,41 & 0,41 & 0,00 & 0,21 & 0,00 & 0,00 \\
\hline 12 & 0,37 & 0,37 & 0,00 & 0,00 & 0,00 & 0,00 \\
\hline 13 & 0,00 & 0,34 & 0,00 & 0,00 & 0,00 & 0,00 \\
\hline 14 & 0,00 & 0,31 & 0,00 & 0,00 & 0,00 & 0,00 \\
\hline 15 & 0,00 & 0,28 & 0,00 & 0,00 & 0,00 & 0,00 \\
\hline$>15$ & 0,00 & 0,00 & 0,00 & 0,00 & 0,00 & 0,00 \\
\hline
\end{tabular}

Tabel 4.

Coupling Multiplier

\begin{tabular}{ccc}
\multicolumn{3}{c}{ Coupling Multiplier } \\
\hline Tipe Coupling & \multicolumn{2}{c}{$\mathrm{CM}$} \\
& $\mathrm{V}<75 \mathrm{~cm}$ & $\mathrm{~V} \geq 75 \mathrm{~cm}$ \\
\hline Baik (Good) & 1,00 & 1,00 \\
Sedang (Fair) & 0,95 & 1,00 \\
Jelek (Poor) & 0,90 & 0,90 \\
\hline
\end{tabular}

Lifting Index adalah estimasi sederhana terhadap resiko cidera yang diakibatkan oleh overexertion Berdasarkan berat beban dan nilai RWL dapat ditentukan besarnya LI.

Aktivitas mengangkat dengan LI > 1 (moderately stressful task), akan meningkatkan resiko terhadap keluhan sakit pinggang (low back pain), oleh karena itu, maka beban kerja harus didesain sedemikian rupa sehingga nilai $\mathrm{LI} \leq 1$. Beban kerja dengan nilai $\mathrm{LI}>1$, mengandung resiko keluhan sakit pinggang, sedangkan untuk nilai LI>3 (highly stressful task), sudah dapat dipastikan terjadinya overexertion (Waters \& Anderson, 1996b dalam Tarwaka).

Adapun tujuan yang akan dicapai melalui penelitian ini adalah :

a. Menghitung berat beban yang direkomendasikan dapat diangkat oleh operator secara manual berdasarkan perhitungan metode RWL.

b. Menentukan kategori resiko cedera yang diakibatkan oleh pekerjaan berat berdasarkan nilai Lifting Index.

c. Memberikan usulan perbaikan pada sistem kerja sehingga dapat mengurangi cedera pada pekerja penyusunan box secara manual di area converting \#6 PT. Indah Kiat Pulp and Paper,Tbk.

\section{Methodologi}

Tahapan yang dilakukan dalam penelitian ini adalah sebagai berikut:

- Tahap Studi Pendahuluan, meliputi :

1. Perumusan Masalah yang akan diteliti,

2. Tinjauan Pustaka dan Tinjauan Lapangan,

3. Perumusan Tujuan Penelitian.

- Tahap Identifikasi, meliputi :

1. Pemilihan Metode yang akan digunakan,

2. Penentuan Tempat Penelitian,

3. Penentuan Data yang dibutuhkan.

- Tahap Pengumpulan Data, meliputi :

1. Penentuan responden dan total responden,

2. Pengambilan data kondisi postur kerja,

- Tahap Pengolahan dan Analisa data, meliputi :

1. Melakukan perhitungan factor pengali untuk penentuan RWL,

2. Melakukan perhotungan lifting index,

3. Menganalisis hasil pengolahan.

- Tahap Penutup.

SURYA TEKNIKA Vol. 1 No. 4, Juni 2016 : 49 - 55 


\section{Hasil dan Pembahasan}

Berdasarkan hasil data kondisi rill yang ada dilapangan pada proses ini operator memindahkan box yang sudah terisi dari meja konveyor ke atas pallet. Setiap box berisi 5-10 ream kertas yang beratnya 12-24 kg. Satu pallet terdiri dari 60 box dengan posisi menumpuk yaitu $4 \times 3$ dengan 5 tumpukan, tetapi yang akan dianalisa adalah berat beban $12 \mathrm{~kg}$ karena apabila berat beban ini telah melebihi berat beban yang direkomendasikan tentu saja beban yaang lebih berat juga pasti akan melebihi berat beban yang direkomendasikan.

Berikut penjelasan faktor pengali yamg dibutuhkan untuk mendaapatkan nilai RWL, yaitu :

\section{Beban kerja yang diangkat}

Setiap box berisi 5-10 ream kertas yang beratnya $12-24 \mathrm{~kg}$. Satu pallet terdiri dari 60 box dengan posisi menumpuk yaitu $4 \times 3$ dengan 5 tumpukan, tetapi yang akan dianalisa adalah berat beban $12 \mathrm{~kg}$.

\section{Jarak Horizontal}

Faktor pengali horizontal ini didapatkan dari rumus $\mathrm{HM}=25 / \mathrm{H}$, dimana nilai $\mathrm{H}$ disini adalah nilai yang menyatakan variabel jarak horizontal. Nilai variabel jarak horizontal didapatkan dari titik nol antara dua kaki dengan proyeksi benda ke lantai. Komponen jarak horizontal destination atau tujuan adalah sbb :

Tabel 5.

\begin{tabular}{ccc}
\multicolumn{3}{c}{ Jarak Horizontal } \\
\hline No. & Asal (cm) & Tujuan $(\mathrm{cm})$ \\
\hline 1 & 40 & 85 \\
2 & 40 & 85 \\
3 & 40 & 85 \\
4 & 40 & 85 \\
5 & 40 & 85 \\
\hline
\end{tabular}

Maka diperoleh faktor pengali horizontal seperti tabel berikut :

Tabel 6.

Faktor Pengali Horizontal

\begin{tabular}{ccc}
\multicolumn{3}{c}{ Faktor Pengali Horizontal } \\
\hline No. & Asal $(\mathrm{cm})$ & Tujuan $(\mathrm{cm})$ \\
\hline 1 & 0,625 & 0,295 \\
2 & 0,625 & 0,295 \\
3 & 0,625 & 0,295 \\
4 & 0,625 & 0,295 \\
5 & 0,625 & 0,295 \\
\hline
\end{tabular}

\section{Jarak Vertikal}

Jarak vertikal dinyatakan sebagai ketinggian letak beban yang akan diangkat oleh pekerja. Pada lokasi asal, jarak vertikalnya adalah ketinggian meja sebagai landasan box dari lantai. Sedangkan pada lokasi tujuan, pekerja melakukan pengangkatan dengan cara membungkuk, dimana resiko yang tinggi terjadi adalah pada saat pengangkatan tumpukan produk paling bawah.

Jarak vertikal pada lokasi asal dan tujuan adalah sbb :

Tabel 7.

\begin{tabular}{ccc}
\multicolumn{3}{c}{ Jarak Vertikal } \\
\hline No. & Asal $(\mathrm{cm})$ & Tujuan $(\mathrm{cm})$ \\
\hline 1 & 85,5 & 14 \\
2 & 85,5 & 39 \\
3 & 85,5 & 64 \\
4 & 85,5 & 89 \\
5 & 85,5 & 114 \\
\hline
\end{tabular}

Faktor pengali vertikal didapatkan dari rumus VM $=(1-0.003 \mathrm{I} \mathrm{V}-75 \mathrm{I})$. Nilai V merupakan nilai variabel jarak vertikal, yaitu jarak yang dihitung dari posisi benda terhadap lantai pada kondisi origin dan destination.

Maka diperolah faktor pengali vertikalnya adalah sbb :

Tabel 8.

Faktor Pengali Vertikal

\begin{tabular}{ccc}
\hline No. & Asal $(\mathrm{cm})$ & Tujuan $(\mathrm{cm})$ \\
\hline 1 & 0,968 & 0,817 \\
2 & 0,968 & 0,893 \\
3 & 0,968 & 0,997 \\
4 & 0,968 & 0,958 \\
5 & 0,968 & 0,883 \\
\hline
\end{tabular}

\section{Jarak Perpindahan}

Jarak perpindahan dinyatakan sebagai selisih jarak vertikal pada lokasi asal dan lokasi tujuan. Nilai jarak perpindahan dihitung sebagai jarak perpindahan terjauh yang mungkin terjadi dimana resiko menjadi lebih tinggi. Jarak perpindahan untuk lokasi asal adalah 0 sedangkan jarak perpindahan untuk lokasi tujuan adalah sbb: 
Tabel 9.

\begin{tabular}{cc} 
& Jarak Perpindahan Tujuan \\
\hline No & D (cm) \\
\hline 1 & 71,5 \\
2 & 46,5 \\
3 & 21,5 \\
4 & 3,5 \\
5 & 21,5 \\
\hline
\end{tabular}

Faktor pengali jarak perpindahan didapatkan dari rumus $\mathrm{DM}=0,82+(4,5 / \mathrm{D})$. Maka diperoleh faktor pengali jarak perpindahan untuk daerah asal mendekati nilai 1 dan untuk daerah tujuan sbb :

Tabel 10.

Faktor Pengali Jarak Perpindahan

\begin{tabular}{cc}
\multicolumn{2}{c}{ Faktor Pengali Jarak Perpindahan } \\
\hline No & DM \\
\hline 1 & 0,883 \\
2 & 0,917 \\
3 & 1,000 \\
4 & 1,000 \\
5 & 1,000 \\
\hline
\end{tabular}

\section{Sudut Asimetri}

Sudut asimetri merupakan sudut yang dibentuk oleh garis segitiga (garis lurus tepat di depan pekerja) dengan garis asimetri (garis yang menunjuk arah pengambilan beban). Karena pekerja berhadapan langsung dengan box yang akan dipindahkan maka sudut asimetri asalnya adalah 0 derajat sedangkan sudut asimetri tujuannya adalah 90 derajat karena operator harus meletakkan boxtersebut tepat di sebelah pekerja. Sudut asimetri pada lokasi asal dan lokasi tujuan adalah sbb :

Tabel 11.

Sudut Asimetri

\begin{tabular}{ccc}
\hline No. & Asal & Tujuan \\
\hline 1 & 0 & 90 \\
2 & 0 & 90 \\
3 & 0 & 90 \\
4 & 0 & 90 \\
5 & 0 & 90 \\
\hline
\end{tabular}

Faktor pengali asimetri didapatkan dari rumus $\mathrm{AM}=1-(0,0032 \mathrm{~A})$, dimana nilai $\mathrm{A}$ adalah sudut yang terbentuk antara posisi sagital tubuh pekerja dengan benda atau objek yang diangkat. Dengan demikian faktor pengali asimetrinya adalah sbb :

Tabel 12.

Faktor Pengali Sudut Asimetri

\begin{tabular}{ccc}
\hline \multicolumn{3}{c}{ Faktor Pengali Sudut Asimetri } \\
\hline No. & Asal & Tujuan \\
\hline 1 & 1 & 0,712 \\
2 & 1 & 0,712 \\
3 & 1 & 0,712 \\
4 & 1 & 0,712 \\
5 & 1 & 0,712 \\
\hline
\end{tabular}

\section{Faktor Pengali Frekuensi}

Faktor pengali frekuensi didapatkan berdasarkan jumlah beban yang diangkat permenit dan lamanya waktu pengangkatan atau durasinya. Rata-rata jumlah box yang diangkat setiap harinya adalah sekitar 10.080 box. Berdasarkan jumlah itu maka rata-rata beban yang diangkat perjamnya adalah 420 box dan rata-rata beban yang diangkat adalah 7 box permenitnya . Sedangkan durasi pengangkatan box ini adalah dengan jenis durasi panjang. Maksudnya adalah waktu kerja antara 2-8 jam dan diikuti dengan kelonggaran waktu istirahat menurut standar yaitu 1 jam.

Bersdasarkan tabel 3 yaitu tabel pengali frekuensi didapatkan bahwa nilai FM dari kondisi tersebut adalah 0,22.

\section{Faktor Pengali Kopling}

Faktor pengali kopling didapatkan dari tabel 4 pada tabel tersebut kualitas kopling terbagi atas tiga kategori yaitu baik, sedang dan jelek. Kualitas kopling ini dinyatakan sebagai kualitas pegangan barang dengan menggunakan dua tangan sebagai pemegang. Untuk pengangkatan box ini diangkat dengan menggunakan dua tangan tanpa adanya pegangan khusus dengan durasi panjang yang waktu kerjanya antara 2-8 jam. Berdasarkan pohon pengambilan keputusan kualitas kopling maka untuk kondisi origin dan destination kualitas kopling yang didapatkan adalah buruk karena objek yang diangkat adalah objek bebas dengan ukuran yang cukup besar sehingga diperoleh nilai 0,90 .

$$
\begin{aligned}
\mathrm{RWL}= & \mathrm{LC} \times \mathrm{HM} \times \mathrm{VM} \times \mathrm{DM} \times \mathrm{AM} \times \mathrm{FM} \\
& \mathrm{x} \mathrm{CM}
\end{aligned}
$$

Nilai $\mathrm{L}=12 \mathrm{~kg}$

$\mathrm{LI} \quad=\mathrm{L} / \mathrm{RWL}$

SURYA TEKNIKA Vol. 1 No. 4, Juni 2016 : 49 - 55 
Dimana nilai $\mathrm{L}$ adalah nilai berat beban yang diangkat, beban yang diangkat adalah sebesar 12-24 kg. Tapi yang dihitung adalah untuk berat beban $12 \mathrm{~kg}$. Sedangkan nilai RWL adalah berat beban yang direkomendasikan.

Dengan menggunakan rumus di atas, maka diperoleh nilai RWL dan LI daerah asal sebagai berikut :

Tabel 13.

Pengolahan RWL dan LI Daerah Asal

\begin{tabular}{cccccccccc}
\hline No & LC & HMI & VM & DM & AM & FM & CM & RWL & LI \\
\hline 1 & 23 & 0,625 & 0,968 & 0,82 & 1 & 0,22 & 0,9 & 2,259 & 5,31 \\
\hline
\end{tabular}

Sedangkan nilai RWL dan LI daerah asal untuk setiap box adalah sbb:

Tabel 14.

Pengolahan RWL dan LI Daerah Tujuan

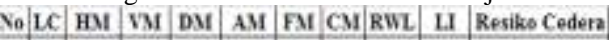
\begin{tabular}{|l|l|l|l|l|l|l|l|l|l|l|}
\hline 1 & 23 & 0,295 & 0.817 & 0,893 & 0,712 & 0,22 & 0,9 & 0,69 & 17,39 & Overextion \\
\hline
\end{tabular}

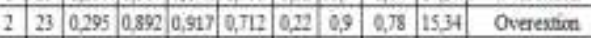
\begin{tabular}{|l|l|l|l|l|l|l|l|l|l|l|l|}
\hline 3 & 23 & 0,295 & 0,992 & 1,000 & 0,712 & 0,22 & 6,9 & 0,95 & 12,65 & Overession \\
\hline
\end{tabular}

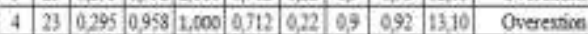

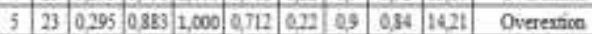

Dari hasil yang didapatkan pada sistem kerja untuk penyusunan box di PT. Indah Kiat Pulp and Paper, Tbk Perawang pada kondisi sekarang maka dapat disimpulkan bahwa sistem kerja yang sudah ada kurang baik dan kurang ergonomis bagi pekerja. Hali ini dapat dilihat dari nilai RWL yang jauh lebih kecil dari berat beban yang diangkat sehingga memberikan nilai LI yang besar dari 3. Untuk itu perlu dirancang usulan sistem kerja yang baru dengan lebih memperhatikan kesehatan dan keselamatan pekerja. Usulan yang diberikan antara lain :

a. Rekomendasi Berat Beban Yang

Diangkat

Pada penyusunan box di PT. Indah Kiat Pulp and Paper, Tbk Perawang dengan berat beban yang diangkat berkisar $12-24 \mathrm{~kg}$. Dimana satu box berisi 5-10 ream kertas. Dengan berat beban yang ada maka kemungkinan akan timbulnya cedera pada pekerja akan semakin besar sehingga diperlukan pengurangan berat beban yang diangkat hingga mendekati $0,95 \mathrm{~kg}$. Namun tidak mungkin melakukan pengurangan berat beban, karena dengan berat beban tersebut hanya memungkinkan diisi dengan 1 ream kertas.

b. Rekomendasi Jarak Horizontal

Jarak horizontal untuk posisi asal adalah
$40 \mathrm{~cm}$, sehingga diperoleh faktor pengali horizontal sebesar 0,625. Sedangkan jarak horizontal untuk daerah tujuan adalah 85 $\mathrm{cm}$, sehingga diperoleh faktor pengali horizontal sebesar 0,295. Agar faktor pengali horizontal mendekati nilai 1 , maka jarak horizontal yang direkomendasikan adalah mendekati $25 \mathrm{~cm}$, baik untuk daerah asal maupun daerah tujuan. Tetapi karena nilai $25 \mathrm{~cm}$ ialah jarak yang terlalu kecil untuk besar beban yang diangkat, maka direkomendasikan untuk mengurangi jarak menjadi $50 \mathrm{~cm}$. Dengan jarak $50 \mathrm{~cm}$ ini faktor pengali yang diperoleh akan mendekati 1 sehingga resiko terjadinya cedera akan semakin berkurang.

c. Rekomendasi Jarak Vertikal

Jarak vertikal pada daerah asal untuk kondisi rill adalah $85,5 \mathrm{~cm}$ dengan faktor pengali vertikal sebesar 0,988 . Sedangkan jarak vertikal pada daerah tujuan untuk box 1, ke-2, ke-3, ke-4, dan ke-5 berturut-turut adalah $14 \mathrm{~cm}, 39 \mathrm{~cm}, 64 \mathrm{~cm}, 89 \mathrm{~cm}$, dan 114 $\mathrm{cm}$ dan diperoleh faktor pengali sebesar $0,817,0,892,0,997,0,958$, dan 0,883 .

Dari hasil faktor pengali vertikal, dapat dilihat bahwa jarak vertikal yang ada umumnya belum baik sehingga perlu dilakukan perbaikan untuk mendapatkan faktor pengali vertikal yang bernilai 1 yaitu pada ketinggian $75 \mathrm{~cm}$. Tetapi untuk ketinggian pallet $75 \mathrm{~cm}$ yang dipakai tidak mungkin ada, sehingga direkomendasikan untuk menambah ketinggian pallet hingga $20 \mathrm{~cm}$.

d. Rekomendasi Jarak Perpindahan

Jarak perpindahan untuk daerah asal adalah 0 karena benda belum dipindahkan. Sedangkan untuk daerah tujuan jarak perpindahannya adalah $71,5 \mathrm{~cm}, 46,5 \mathrm{~cm}$, $21,5 \mathrm{~cm}, 3,5$ dan $21,5 \mathrm{~cm}$. Sehingga diperoleh faktor pengali jarak perpindahan $0,883,0,917,1,1$, dan 1. Dari hasil pengolahan data dapat dilihat bahwa jarak perpindahan yang baik adalah nilai jarak perpindahan yang semakin mendekati nilai 0 . Semakin besar jarak perpindahan maka resiko terjadinya cedera pada pekerja akan semakin besar pula.

e. Rekomendasi Sudut Asimetri

Sudut asimetri yang terbentuk pada pengangkatan box untuk daerah asal adalah 0 derajat dan diperoleh faktor pengali asimetri sebesar 1 . Sedangkan untuk daerah tujuan adalah 90 derajat dan diperoleh faktor

SURYA TEKNIKA Vol. 1 No. 4, Juni 2016 : 49-55 
pengali asimetri sebesar 0,712. Dari hasil yang diperoleh ini maka dapat diketahui bahwa sudut asimetri yang terbentuk pada saat penagangkatan box yang baik adalah sebesar 0 derajat. Artinya tidak ada perputaran yang dilakukan oleh pekerja pada saat mengangkat box tersebut.

f. Rekomendasi Frekuensi

Frekuensi pengangkatan box permenitnya adalah 7 box dalam durasi pengangkatan yang kurang dari 1 jam dengan jarak vertikal lebih besar dari 420 box maka diperoleh faktor pengali frekuensi sebesar 0,22. Kondisi ini masih belum baik karena efek pengangkatan kurang dari 2 box permenitnya atau dapat pula diperbaiki dengan menambah pekerja sehingga dapat mengurangi resiko terjadinya cedera pada pekerja.

g. Rekomendasi Kualitas Kopling

Berdasarkan pohon keputusan penentuan kopling maka jenis kopling yang ada di perusahaan ini berjenis baik. Dengan ukuran box $(31 \times 22 \times 25) \mathrm{cm}$.

Dari hasil pengolahan data didapatkan bahwasanya untuk berat box melebihi yang batas rekomendasikan untuk dilakukan pekerjaan penyusunan box secara manual, sedangkan berat box ialah suatu ketetapan dalam quality perusahaan. Jika pekerjaan penyusunan box secara manual tetap dilakukan, maka cara untuk menjaga terjadinya resiko cedera punggung pada karyawan ialah dengan menyesuiakan jarak dan ukuran conveyor dengan pallet berdasarkan dari hasil perhitungan metode Recommended Weight Limit (RWL).

\section{Simpulan}

Berdasarkan hasil analisa dan pengamatan serta pengolahan data yang telah dilakukan, maka dapat disimpulkan :

1. Berat beban yang diangkat oleh pekerja pada proses penyusunan box secara manual melebihi berat beban yang direkomendasikan menurut perhitungan metode RWL. Yaitu saat ini seberat 12$24 \mathrm{~kg}$, sedangkan berdasarkan perhitungan metode RWL maksimal adalah $0,95 \mathrm{~kg}$.

2. Berdasarkan hasil perhitungan dengan menggunakan perhitungan metode RWL. maka diperoleh nilai LI yang lebih dari 3 Sehingga perlu rekondisi sistem kerja pada proses penyusunan box secara manual. Karena pekerjaan saat ini memiliki resiko cedera yang sangat tinggi (highly streefull task)

3. Usulan perbaikan berdasarkan perhitungan metode RWL sebagai berikut.

Untuk berat beban yang direkomendasikan adalah $0,95 \mathrm{~kg}$ dan jarak antara conveyor dan pallet yaitu $25 \mathrm{~cm}$ serta untuk ketinggian pallet ditambah hingga 20 $\mathrm{cm}$. Usulan ini dapat mengurangi resiko cedera punggung pada pekerja.

\section{Saran}

1. Kegiatan mengangkat beban dengan cara membungkuk dapat menyebabkan cedera pada tulang punggung pekerja. Oleh karena itu posisi tempat mengangkat dan menaruh beban harus dengan ketinggian tertentu.

2. Diharapkan kepada perusahaan agar lebih memperhatikan kesehatan dan keselamatan pekerja dengan memperbaiki sistem kerja dan memberikan alat bantu pada area penyusunan box manual.

\section{Daftar Pustaka}

[1] Alif Dany Hasan, Hubungan Composite Lifting Indeks Terhadap Keluhan Sistem Muskuluskeletal Pada Pekerja Palleting Di Area Aqua 1500 ml Di PT. Tirta Investama. Laporan Khusus, 2010.

[2] Denny Astrie Anggraini, Perhitungan Berat Beban Yang Direkomendasikan Menurut Persamaan NIOSH Untuk Pengangkatan Doos Oleh Operator Pada Line Packaging Di PT. Selamat Sempurna. Tbk , Laporan Kerja Praktek 1, 2006.

[3] Maidiawati, Analisis Manual Material Handling Dengan Menggunakan Metode Recommended Weight Limit (RWL) Pada Bagian Produksi Packing Untuk Produk Flooring Di CV. Kosima Arta, Tugas Akhir UBH, 2005.

[4] Sutalaksana, Iftikar Z, dkk, Teknik Tata Cara Kerja, Jurusan Teknik Industri ITB, Bandung, 1970.

[5] Waters, Thomas R, Application Manual For The Revised NIOSH Lifting Equation, Public Health Service Center, Ohio, 1994. 